\title{
INCLUSÃO ESCOLAR NO NORDESTE: O QUE REVELAM OS DADOS DO CENSO ESCOLAR ENTRE 2009 E 2013
}

\author{
INCLUSIVE EDUCATION IN THE NORTHEASTERN REGION: WHAT
} THE SCHOOL CENSUS DATA BETWEEN 2009 AND 2013 REVEALS

\author{
Vanessa Dias Bueno de Castro ${ }^{1}$ \\ Maria Júlia Canazza Dall'Acqua ${ }^{2}$
}

\begin{abstract}
Resumo
Este artigo é parte da dissertação intitulada "Inclusão Escolar no Período de 2009 a 2013 sob a Perspectiva das Matrículas no Censo Escolar no Brasil”, e tem como objetivos analisar os efeitos da "Política Nacional de Educação Especial na Perspectiva da Educação Inclusiva", de 2008, no quadro de matrículas de alunos público-alvo da educação especial da Região Nordeste por meio dos dados das Sinopses Estatísticas dos Censos Escolares entre 2009 e 2013 e a distribuição dessas matrículas entre as modalidades de ensino. De natureza descritiva, foram selecionados os dados da Região Nordeste referentes às matrículas de alunos público-alvo da educação especial, distribuídas entre Classes Comuns do Ensino Regular, Escolas Exclusivamente Especializadas e Classes Especiais do Ensino Regular, bem como entre áreas urbanas e áreas não urbanas. Os resultados mostram reduções nas matrículas na Educação Básica, mas aumentos consecutivos para alunos público-alvo da educação especial.
\end{abstract}

Palavras-chave: Educação Especial. Inclusão Escolar. Política Educacional. Censo Escolar. Matrículas.

\begin{abstract}
This article is part of a dissertation entitled "Inclusão Escolar no Período de 2009 a 2013 sob a Perspectiva das Matrículas no Censo Escolar no Brasil", and aimed to analyze the effects of "Política Nacional de Educação Especial na Perspectiva da Educação Inclusiva", from 2008, in relation to the number of enrollments of the target audience of special education in Northeastern Region using data obtained in Abstracts School Census Statistics from 2009 to 2013 and the distribution of enrollments among the modalities of teaching. It's a research descriptive type, data refering to the Northeastern Region was selected, regarding the number of enrollments of the target audience of special education, distributed among Common Regular Education Classes, Exclusively Specialized Schools and Special Classes of Regular Education, as well between urban and non urban areas. The results shows decreases in enrollments in basic education, but consecutive increases in target audience on special education.

\footnotetext{
1 Mestra em Educação Escolar pela UNESP, Doutoranda em Educação pela USP. E-mail: van.bcastro@gmail.com

${ }^{2}$ Possui mestrado em Educação Especial (Educação do Indivíduo Especial) pela Universidade Federal de São Carlos (1987) e doutorado em Programa de Pós Graduação Em Educação pela Universidade Federal de São Carlos (1997). Atualmente é professora assistente doutora II aposentada da Universidade Estadual Paulista Júlio de Mesquita Filho. E-mail: juliacandal@gmail.com
} 
Keywords: Special Education. Inclusive Education. Educational Policy. School Census. Enrollments.

\section{Introdução}

Ao final da década de 1990, conforme Mendes (2010), a Educação Especial brasileira passou a fazer parte do contexto de reforma do sistema educacional e do entusiasmado debate sobre a educação inclusiva. Nessa perspectiva, Matos e Mendes (2014) apontam que o princípio da inclusão escolar globalizou-se, e as suas teorias e práticas começaram a ser defendidas em muitos países, uma vez que é fundamental a construção de uma sociedade inclusiva para a consolidação e o desenvolvimento de um estado democrático. A Educação Inclusiva, entendida como parte essencial desse estado democrático, aponta para a necessidade de reformas educacionais em diversos âmbitos.

A partir de então, surgiram importantes políticas, documentos e resoluções acerca da temática da educação inclusiva, tanto no contexto nacional quanto no mundial e, no processo de consolidação de políticas brasileiras para uma Educação Inclusiva, faz-se necessário colocar em destaque a "Política Nacional de Educação Especial na Perspectiva da Educação Inclusiva" (BRASIL, 2008), sendo dela decorrentes todas as resoluções e pareceres subsequentes.

Tal política, aprovada em 2008, surgiu no contexto de avanços e lutas sociais que buscam mudanças estruturais e culturais na escola como um todo, a fim de garantir que todos os alunos tenham uma educação de qualidade. Dessa maneira,

\footnotetext{
$\mathrm{Na}$ perspectiva da educação inclusiva, a educação especial passa a integrar a proposta pedagógica da escola regular, promovendo o atendimento às necessidades educacionais especiais de alunos com deficiência, transtornos globais de desenvolvimento e altas habilidades/superdotação. Nestes casos e outros, que implicam em transtornos funcionais específicos, a educação especial atua de forma articulada com o ensino comum, orientando para o atendimento às necessidades educacionais especiais desses alunos. (BRASIL, 2008, p.09).
}

Conforme Bueno e Meletti (2013), o documento procurou definir melhor quais são os alunos Público-Alvo da Educação Especial (PAEE). As pessoas com deficiência são aquelas que possuem impedimentos de longo prazo, seja de natureza física, mental ou sensorial que, ao se deparar com diversas barreiras, podem ter sua participação efetiva, tanto na escola quanto na sociedade, limitada. Os alunos com transtornos globais do desenvolvimento, por sua vez, são os que apresentam alterações qualitativas das interações sociais recíprocas e na 
comunicação, um repertório de interesses e atividades restrito, estereotipado e repetitivo. Alunos com autismo, síndromes do espectro do autismo e psicose infantil estão incluídos nesse grupo. Por fim, alunos com altas habilidades/superdotação são aqueles que demonstram potencial elevado em qualquer uma das seguintes áreas, isoladas ou combinadas: intelectual, acadêmica, liderança, psicomotricidade e artes, além de apresentar grande criatividade, envolvimento na aprendizagem e realização de tarefas em áreas de seu interesse. (BRASIL, 2008).

Bueno (2013) faz um importante apontamento sobre a referida política. Segundo o autor, na medida em que se trata de uma proposição de governo e não de Estado, não dependendo da aprovação do Poder Legislativo ou do Conselho Nacional de Educação (CNE), ela pode ou não ser seguida. Nesse sentido, a política não possui caráter fático de legislação, haja vista que “[...] não tem poder sobre as políticas das unidades federadas e dos municípios, servindo como documento norteador [...].” (BUENO, 2013, p.31).

Com o objetivo de realizar um amplo levantamento sobre as escolas de educação básica do país, o Instituto Nacional de Estudos e Pesquisas Educacionais Anísio Teixeira (Inep), em colaboração com a União, os Estados, o Distrito Federal e os municípios, realiza anualmente o Censo Escolar. Tal Censo é o levantamento estatístico educacional brasileiro mais importante, uma vez que fornece dados e informações relativas à Educação Básica capazes de subsidiar a elaboração de análises, diagnósticos, bem como o planejamento do sistema educacional do Brasil.

No que diz respeito aos alunos PAEE, “[...] o Educacenso coleta informações sobre a condição física, sensorial e intelectual dos estudantes e professores, fundamentado no artigo 1 da Convenção sobre os Direitos das Pessoas com Deficiência - ONU/2006 e no artigo 5. ${ }^{\circ}$ do Decreto n. ${ }^{5} 5.296 / 2004$." (BRASIL, 2014). Por meio dos dados colhidos, é possível identificar o número de alunos que necessitam de material didático em diversos formatos de acessibilidade, de recursos de tecnologia assistiva e do Atendimento Educacional Especializado (AEE), por exemplo.

Os dados obtidos a partir da coleta feita pelo Censo Escolar são agrupados de diversas maneiras. No presente trabalho, destacam-se as divisões das matrículas por dependência administrativa, que é o âmbito de subordinação administrativa da escola, ou seja, se a escola é de responsabilidade federal, estadual, municipal ou privada (que pode ser particular, comunitária, confessional ou filantrópica), e por modalidades de ensino (totalidade da 
Educação Básica, Escolas Exclusivamente Especializadas (EEE), Classes Especiais do Ensino Regular e Classes Comuns do Ensino Regular).

Por meio do Censo Escolar é possível conhecer a situação educacional do país como um todo, de suas escolas, profissionais e alunos. Além disso, os dados apresentados são capazes de subsidiar a elaboração ou o aperfeiçoamento de políticas públicas educacionais e execução de programas na área da educação.

De acordo com o sítio eletrônico do Inep (EDUCACENSO), os dados obtidos no Censo Escolar, referentes ao rendimento e movimento escolar dos alunos dos ensinos Fundamental e Médio, somados aos dados obtidos em avaliações como o Sistema de Avaliação da Educação Básica (Saeb) e a Prova Brasil, são utilizados para calcular o Índice de Desenvolvimento da Educação Básica (Ideb), indicador usado como referência para as metas do Plano de Desenvolvimento da Educação (PDE).

São diversas as maneiras de se acessar os dados do Censo Escolar, dentre elas o sistema do Educacenso, o Data Escola Brasil, as Sinopses Estatísticas, os microdados ou por solicitação direta ao Inep, ou seja, os dados são bastante acessíveis.

De acordo com Prieto (2010), embora existam dúvidas sobre possíveis distorções em relação à classificação indevida de alguns alunos como PAEE, são os dados do Censo que nos possibilitam acompanhar a evolução das matrículas de alunos PAEE.

Ainda sobre os questionamentos em relação à coleta dos dados, Bueno e Meletti (2011) afirmam que "as Sinopses Estatísticas que apresentam os dados dos Censos Escolares revelam aspectos imprecisos e ambíguos em sua metodologia de coleta." (BUENO; MELETTI, 2011, p. 375). Entretanto, corroborando o pensamento de Prieto (2010), os autores indicam que esses levantamentos são fundamentais para a elaboração de políticas destinadas a alunos PAEE e são capazes de mostrar a evolução das suas matrículas.

Nesse mesmo âmbito, conforme Bueno e Meletti (2013), no que tange especificamente à Educação Especial, os dados referentes às matrículas, sejam eles globais, por tipo de deficiência, por tipo de escolarização ou por etapas do ensino básico, “[...] são indicadores importantíssimos para a avaliação das políticas de educação especial em curso [...]." (BUENO; MELETTI, 2013, p.77-78).

Destarte, ainda que pareçam superestimadas, as informações do Censo Escolar da Educação Básica compõem um dos principais indicadores sociais brasileiros que, de acordo com Bueno e Meletti (2013), “[...] são a base para a elaboração, implementação e avaliação das políticas e dos programas de Estado e de governos.” (BUENO; MELETTI, 2013, p.84). 
Nesse contexto, optou-se por apresentar neste artigo uma análise empreendida a partir das matrículas da Região Nordeste do Brasil ${ }^{3}$, referentes aos alunos PAEE, registradas em Escolas Exclusivamente Especializadas (EEE), em Classes Especiais e em Classes Comuns, ambas do Ensino Regular ${ }^{4}$ entre os anos 2009 e 2013. Além das modalidades de ensino, o recorte previu também que o estudo pudesse ocorrer de acordo com as dependências administrativas, a saber: federal, estadual, municipal e privada.

Outra fonte de informações acerca da educação brasileira é o Atlas do Desenvolvimento Humano no Brasil ${ }^{5}$, que apresenta, em seu endereço eletrônico, dados da evolução em proporções, comparando o período de 1991 a 2010. Nesse período, passou de $30,1 \%$ para $54,9 \%$ a parcela da população brasileira adulta com o Ensino Fundamental concluído. No que tange às crianças com 5 e 6 anos que frequentam a escola, o índice passou de $37,3 \%$ para $91,1 \%$, aumento bastante expressivo.

Quanto às regiões brasileiras, o Atlas aponta que as Regiões Norte e Nordeste ainda têm mais de $90 \%$ dos municípios nas faixas de Baixo e Muito Baixo Desenvolvimento Humano no subíndice de Educação. As Regiões Sudeste e Sul, por sua vez, apresentam uma realidade diferente, posto que mais de $50 \%$ dos municípios possuem Índice de Desenvolvimento Humano Municipal (IDHM) Educação nas faixas Médio e Alto Desenvolvimento Humano. Por fim, a Região Centro-Oeste tem 90\% dos municípios com IDHM Educação nas faixas Médio e Baixo Desenvolvimento Humano.

Ainda no que diz respeito à educação, o Fundo das Nações Unidas para a Infância UNICEF (2014) aponta que o número de crianças em faixa etária de Educação Básica obrigatória (de 4 a 17 anos) fora da escola passava de 3,8 milhões em 2010. Desse total, os dois grupos que registram os maiores índices fora da escola são as crianças de 4 e 5 anos idade para frequentar a pré-escola - e os adolescentes de 15 a 17 anos - grupo que deveria cursar o Ensino Médio. Um dos motivos que contribui para tal fato é a legislação, posto que a obrigatoriedade da matrícula dessas faixas etárias é bastante recente. Entretanto, mesmo o grupo na faixa de 6 a 14 anos, que faz parte das políticas públicas há mais tempo, registra cerca de $3,3 \%$ de crianças e adolescentes fora da escola.

\footnotetext{
${ }^{3}$ A Região Nordeste refere-se à tradicional divisão do Brasil em cinco regiões, quais sejam, Norte, Nordeste, Centro-Oeste, Sudeste e Sul, feita pelo Instituto Brasileiro de Geografia e Estatística (IBGE).

${ }^{4}$ O uso do termo "Ensino Regular" é feito de acordo com a nomenclatura utilizada nas Sinopses Estatísticas do Censo Escolar, do Inep, e será mantido nas análises dos dados, respeitando tal nomenclatura. Entretanto, "regular" pode ser entendido como aquilo que está conforme a lei e, dessa maneira, as escolas especiais que cumprem a lei também seriam regulares. O termo mais adequado seria "Ensino Comum".

5 O Atlas do Desenvolvimento Humano no Brasil é realizado pelo Programa das Nações Unidas para o Desenvolvimento (PNUD), pelo Instituto de Pesquisa Econômica Aplicada (Ipea) e pela Fundação João Pinheiro.
} 
A exclusão escolar, como aponta o UNICEF (2014), reflete as desigualdades existentes na sociedade brasileira. Dessa forma, os mais excluídos são as crianças e jovens negros, que vivem em áreas não urbanas, pobres ou pertencentes às famílias em que os pais ou responsáveis têm pouca ou nenhuma escolaridade; as crianças e adolescentes quilombolas, indígenas, em conflito com a lei ou com deficiência. Em seguida, serão apresentados alguns dados específicos desse último grupo.

Primeiramente, cabe ressaltar que, como indica o UNICEF (2012), “[...] não existem estatísticas que permitam mensurar a quantidade exata de crianças com deficiência que ainda permanecem fora da escola no Brasil [...].”(UNICEF, 2012, p.27). Nesse contexto, ressalta que as mais afetadas são as crianças com deficiência severa. Além disso, existe uma dificuldade na continuidade dos estudos depois do Ensino Fundamental, uma vez que poucas escolas de Ensino Médio oferecem atendimentos para alunos com deficiência. Problemas com transporte de crianças com deficiência também são muito frequentes.

Em relação aos dados educacionais totais do Brasil, de acordo com o UNICEF (2014), no que tange à população que precede o grupo das crianças que pertencem ao Ensino Fundamental - ou seja, crianças de 4 e 5 anos - a Região Nordeste registrou 242,9 mil crianças fora da escola.

O grupo de crianças com idades entre 6 e 10, correspondentes aos anos iniciais do Ensino Fundamental, é o que possui os maiores índices percentuais de matrículas: 97,2\%, sendo no Nordeste 128,7 mil matrículas. Ainda sobre essa faixa etária, o UNICEF (2014) atenta para o fato de que a localização foi bastante influente nos índices de exclusão escolar, uma vez que, enquanto as crianças que viviam em áreas urbanas totalizavam 97,6\% de presença na escola, as que viviam em áreas não urbanas atingiam somente 95,3\%.

Ainda em conformidade com o UNICEF (2014), no grupo etário que corresponde aos anos finais do Ensino Fundamental, qual seja, crianças e adolescentes de 11 a 14 anos, a taxa de frequência nas escolas em 2010 chegou a 96,1\%. As Regiões Norte e Nordeste tiveram os menores percentuais de frequência - 94,1\% e 95,9\%, respectivamente - e as Regiões Sudeste e Nordeste registraram os maiores números de crianças fora da escola (187,2 mil e 169 mil).

No que tange ao último grupo etário incluído na obrigatoriedade da escolarização, adolescentes de 15 a 17 anos, o UNICEF (2014) aponta que em 2010 o índice de frequência foi de $83,3 \%$, o que indica que cerca de 1,7 milhão de pessoas nessa faixa etária estava fora da escola.

Em relação aos fatores que contribuem para a exclusão escolar, de acordo com o UNICEF (2012), estão a pobreza, a falta de conexão entre os conteúdos oferecidos pela escola 
e a realidade dos alunos, falta de transporte escolar e o número insuficiente de escolas para atender às demandas, principalmente no campo, onde há um acelerado fechamento das escolas. Embora a população do campo tenha sofrido reduções, “[...] o ritmo do fechamento de escolas tem sido maior do que o da diminuição no número de alunos da educação básica que vivem no campo". (UNICEF, 2014, p.37).

No que diz respeito especificamente às crianças com deficiência, conforme apontam estudos do Instituto de Pesquisa Econômica Aplicada (Ipea) apresentados pelo UNICEF (2014), existe um grande problema em relação à acessibilidade nas escolas - em 2010, somente $18 \%$ das escolas públicas de Educação Básica eram acessíveis para receber alunos com deficiência. Em relação às salas de recursos multifuncionais ${ }^{6}$, os números, no ano da pesquisa, eram baixos - principalmente no campo. Somam-se a isso o preconceito, a discriminação e resistências da escola comum em relação aos profissionais da Educação Especial.

Dessa maneira, verifica-se que, embora a frequência na Educação Básica brasileira seja obrigatória, “[...] milhares de crianças e adolescentes enfrentam obstáculos para ter acesso à escola e um número significativo daqueles que conseguem se matricular acaba por deixar os estudos antes de concluí-los”. (UNICEF, 2014, p.66).

Nesse contexto, o presente trabalho possui as seguintes questões norteadoras: qual é a situação das matrículas dos alunos PAEE no Nordeste após 2008, ano de promulgação da "Política Nacional de Educação Especial na Perspectiva da Educação Inclusiva"? Como estas matrículas encontram-se distribuídas entre Classes Comuns do Ensino Regular, Escolas Exclusivamente Especializadas e Classes Especiais do Ensino Regular em áreas urbanas e em áreas não urbanas?

Para tanto, os objetivos são analisar os efeitos da "Política Nacional de Educação Especial na Perspectiva da Educação Inclusiva" no número de matrículas de alunos PAEE na Região Nordeste; analisar a distribuição dessas matrículas entre as dependências administrativas e as modalidades de ensino no período entre 2009 e 2013; e estabelecer um panorama geral sobre o alcance da "Política Nacional de Educação Especial na Perspectiva da Educação Inclusiva” em relação às matrículas na Região Nordeste.

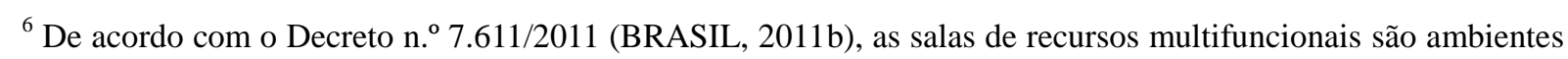
dotados de equipamentos, mobiliários e materiais didáticos e pedagógicos para a oferta do Atendimento Educacional Especializado.
} 


\section{Método}

De natureza descritiva, visando a verificar o impacto da "Política Nacional de Educação Especial na Perspectiva da Educação Inclusiva" (BRASIL, 2008) no número de matrículas de alunos PAEE na Região Nordeste entre os anos 2009 e 2013, esta pesquisa pretendeu apresentar a divisão dessas matrículas entre as dependências administrativas e as modalidades de ensino. Num primeiro momento, foram levantados os dados gerais das matrículas na Educação Básica brasileira e das referentes à Educação Especial. Para tanto, foram empregados dados estatísticos obtidos por meio das Sinopses Estatísticas do Censo Escolar, examinando-os numa perspectiva que leva em consideração tanto o caráter quantitativo dos mesmos, como também a que leva em conta um "olhar" analítico, afeito de forma mais frequente a uma perspectiva de natureza qualitativa. Tais perspectivas, segundo Vilelas (2009), não se constituem em abordagens conflitantes e excludentes.

\section{1 Critérios para coleta de dados}

Estabeleceu-se que, para realizar a coleta de dados da pesquisa, seriam levantados os dados das Sinopses Estatísticas do Censo Escolar do período entre 2009 e 2013, disponíveis no endereço eletrônico do Inep. A escolha do período foi feita em razão de possibilitar que fosse traçado um panorama da situação das matrículas de alunos PAEE na Região Nordeste. Faz-se necessário mencionar que os dados do Censo Escolar de 2013, no momento de realização da coleta de dados, constavam como os últimos disponíveis para consulta.

Outro fator importante para a escolha do período para análise foi a mudança da política de educação especial brasileira em 2008, que passou a ser a "Política Nacional de Educação Especial na Perspectiva da Educação Inclusiva” (BRASIL, 2008). Até então estava em vigor a Política Nacional de Educação Especial de 1994, que orientava o processo de “integração instrucional” e reafirmava "[...] pressupostos construídos a partir de padrões homogêneos de participação e aprendizagem" (BRASIL, 2008). Cabe ressaltar que, no entanto, optou-se por não incluir os dados do Censo Escolar de 2008, ano de mudança na política, devido à diferença nos agrupamentos realizados nas Sinopses Estatísticas, o que inviabilizaria uma análise de confronto entre os dados de 2008 e os dos cinco anos posteriores.

Assim, optou-se por delimitar tal período em função de que o documento considerado um marco para o desenvolvimento da presente pesquisa data do ano de 2008 (BRASIL, 2008) 
e que, portanto, os dados obtidos a partir de então são considerados de relevância. Optou-se também por concentrar a atenção na Educação Básica posto que, havendo a necessidade de um recorte para empreender a busca por informações, o mesmo deveria ocorrer de maneira a permitir que estivesse em evidência o locus no qual há a maior incidência de matrículas de alunos PAEE.

A escolha da Região Nordeste ocorreu devido aos altos índices de crianças e adolescentes em idade escolar fora da escola e por ser uma região brasileira com expressiva porcentagem de matrículas na Educação Básica em áreas não urbanas, como será visto.

\section{2 Procedimentos para análise dos dados}

Após o levantamento de dados, foram construídos gráficos de segmentos, também conhecidos como gráficos de "linhas", e tabelas por meio do programa Excel, a fim de proporcionar melhor leitura e análise dos dados referentes às matrículas de cada modalidade de ensino no período supracitado.

\section{Resultados e discussão}

\section{1 Matrículas no Brasil}

As tabelas a seguir apresentam o total de matrículas no Brasil na Educação Básica (EB) e na Educação Especial no período de 2009 a 2013 (Tabela 1) e a distribuição das matrículas de alunos PAEE entre as modalidades de ensino, quais sejam, Classes Comuns do Ensino Regular, Escolas Exclusivamente Especializadas (EEE) e Classes Especiais do Ensino Regular entre os anos 2009 e 2013 (Tabela 2). 
Tabela 1 - Total de Matrículas na Educação Básica e na Educação Especial no período entre 2009 e 2013

Total de Matrículas na Educação Básica e na Educação Especial (2009 - 2013)

\begin{tabular}{l|c|c|c|c|c}
\hline Modalidade / Ano & $\underline{\mathbf{2 0 0 9}}$ & $\underline{\mathbf{2 0 1 0}}$ & $\underline{\mathbf{2 0 1 1}}$ & $\underline{\mathbf{2 0 1 2}}$ & $\underline{\mathbf{2 0 1 3}}$ \\
\hline Educação Básica & 52.580 .452 & 51.549 .889 & 50.972 .619 & 50.545 .050 & 50.042 .448 \\
\hline Educação Especial & 639.718 & 702.603 & 752.305 & 820.433 & 843.342 \\
\hline
\end{tabular}

Fonte: Sinopses Estatísticas do Censo Escolar entre 2009 e 2013, autoria própria.

Tabela 2 - Número de Matrículas de Alunos Público-Alvo da Educação Especial por Modalidade de Ensino no período entre 2009 e 2013

\begin{tabular}{c|c|c|c|c|c}
\hline \multicolumn{5}{c}{ Número de Matrículas de Alunos Público-Alvo da Educação Especial } \\
\hline Modalidade / Ano & $\underline{\mathbf{2 0 0 9}}$ & $\underline{\mathbf{2 0 1 0}}$ & $\underline{\mathbf{2 0 1 1}}$ & $\underline{\mathbf{2 0 1 2}}$ & $\underline{\mathbf{2 0 1 3}}$ \\
\hline $\begin{array}{c}\text { Classes Comuns do } \\
\text { Ensino Regular }\end{array}$ & 387.031 & 484.332 & 558.423 & 620.777 & 648.921 \\
\hline $\begin{array}{c}\text { Escolas } \\
\text { Exclusivamente } \\
\text { Especializadas }\end{array}$ & 199.257 & 172.016 & 156.385 & 168.488 & 163.968 \\
\hline $\begin{array}{c}\text { Classes Especiais do } \\
\text { Ensino Regular }\end{array}$ & 53.430 & 46.255 & 37.497 & 31.168 & 30.453 \\
\hline
\end{tabular}

Fonte: Sinopses Estatísticas do Censo Escolar entre 2009 e 2013, autoria própria.

No ano de 2009, as matrículas de alunos PAEE representavam cerca de $1,5 \%$ do total de alunos da EB brasileira, correspondente a 639.718, em números absolutos. Em relação à divisão dessas matrículas por modalidades de ensino, verifica-se que 39,5\% frequentavam os Sistemas Segregados de Ensino (SSE), sendo a maior parte nas EEE. Dessa maneira, a maioria desses alunos estava matriculada nas Classes Comuns do Ensino Regular - 60,5\%.

Nos anos decorrentes, na contramão das reduções nos totais de matrículas da EB brasileira, as matrículas de alunos PAEE sofreram consecutivos aumentos, chegando ao total de 843.342 matrículas em 2013, referente a aproximadamente $1,7 \%$ do total - por volta de $31,8 \%$ a mais que em 2009.

De maneira geral, conforme as tabelas, verifica-se que o Censo Escolar registrou redução de 2.538.004 matrículas na EB entre 2009 e 2013. No que diz respeito, particularmente, às matrículas de alunos PAEE ocorreu um movimento inverso, registrando 
aumento de 203.624 matrículas no mesmo período. Quanto à distribuição das matrículas de alunos PAEE, verifica-se redução nas matrículas em Sistemas Segregados de Ensino (SSE), posto que foram registradas 35.289 matrículas a menos em EEE e redução de 22.977 matrículas nas Classes Especiais do Ensino Regular. Na contramão dessas reduções, as Classes Comuns do Ensino Regular totalizaram aumento de 260.890 matrículas.

\section{2 Matrículas da Região Nordeste}

Os gráficos apresentados a seguir expõem a variação das matrículas de alunos PAEE de duas maneiras, quais sejam, de acordo com as modalidades de ensino: EEE, Classes Especiais do Ensino Regular e Classes Comuns do Ensino Regular; e a comparação entre as matrículas em Classes Comuns do Ensino Regular versus matrículas em SSE. Os gráficos auxiliam na compreensão do quadro de matrículas de alunos PAEE da Região Nordeste entre 2009 e 2013.

\section{Gráfico 1- Distribuição por Modalidade de Ensino das Matrículas de Alunos PAEE da Região Nordeste entre 2009 e 2013}

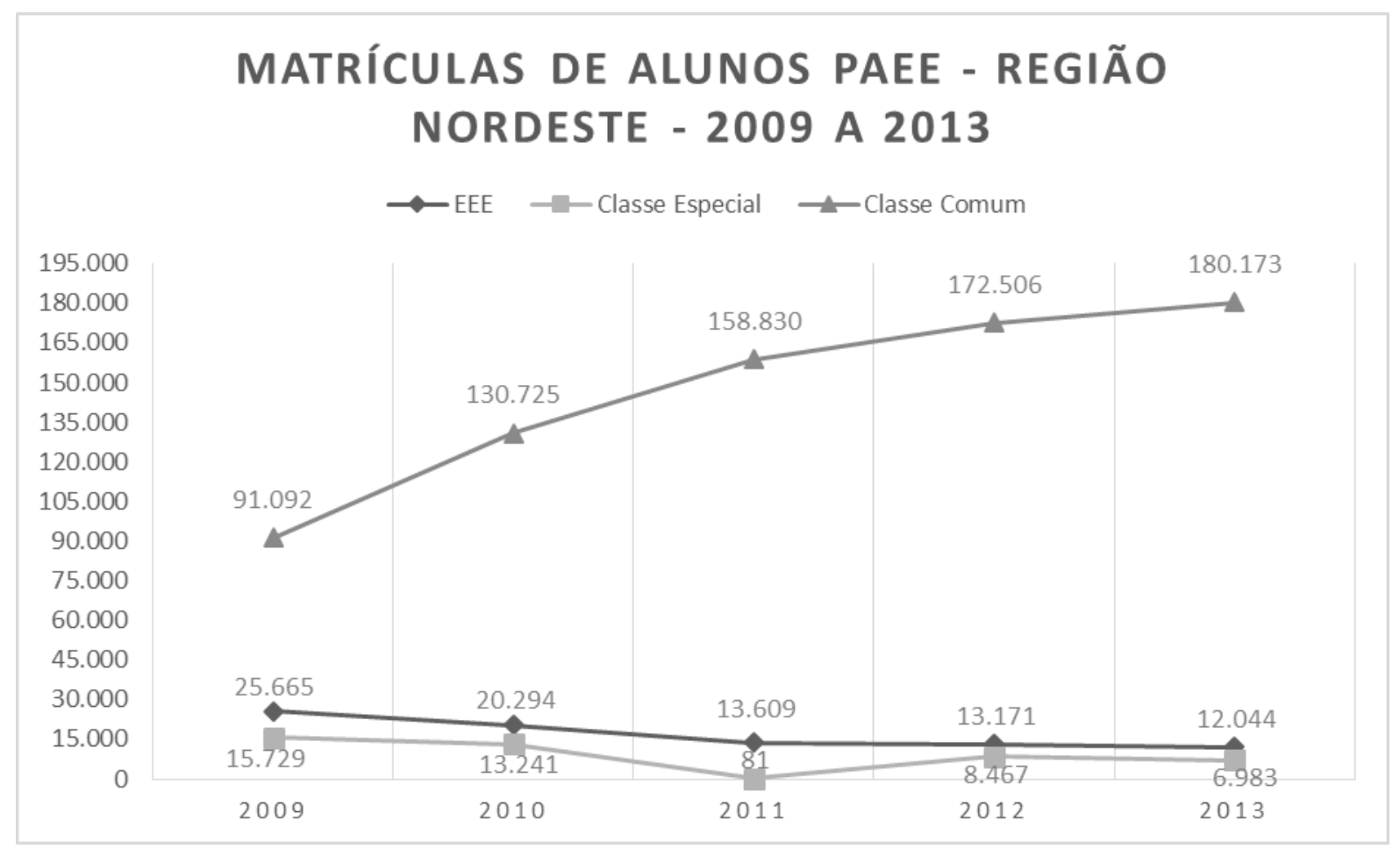

Fonte: Sinopses Estatísticas do Censo Escolar entre 2009 e 2013, autoria própria. 


\section{Gráfico 2 - Comparação das Matrículas de Alunos PAEE em Classe Comum e SSE da Região Nordeste entre 2009 e 2013}

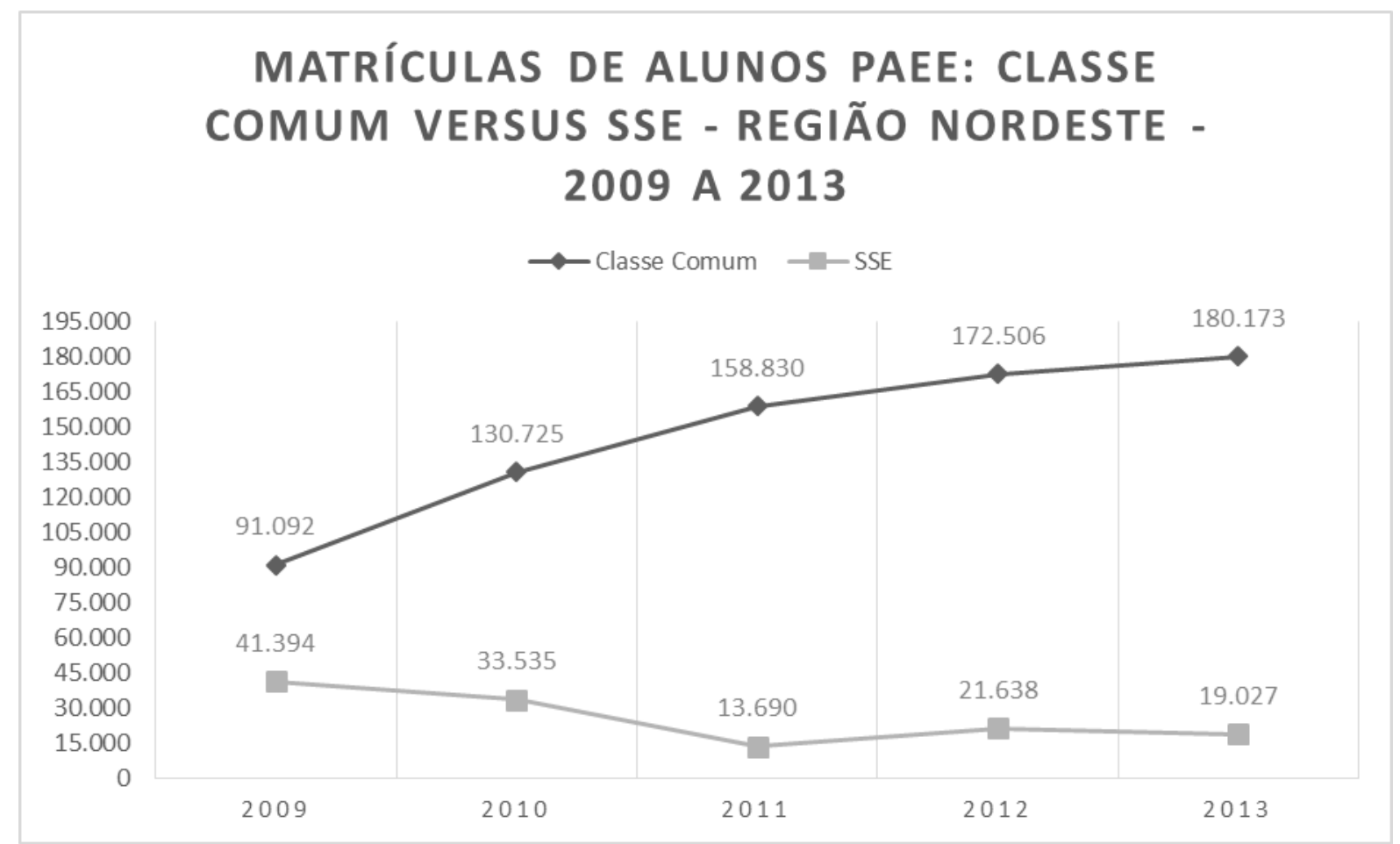

Fonte: Sinopses Estatísticas do Censo Escolar entre 2009 e 2013, autoria própria.

Conforme o Gráfico 1, no que tange às matrículas da Educação Especial na Região Nordeste, os dados apontam para uma redução no número de matrículas em EEE e em Classes Especiais do Ensino Regular totalizando, juntas, 22.367 matrículas a menos em 2013 do que as registradas em 2009. Na contramão, os dados apresentados registram consecutivos aumentos no número de matrículas de alunos PAEE em Classes Comuns do Ensino Regular. Em 2009, eram 91.092 matrículas nessa modalidade de ensino, já em 2013 foram registradas 180.173 matrículas, ou seja, aumento de aproximadamente 49,4\% - 89.081 matrículas a mais.

No que tange à divisão das matrículas de alunos PAEE entre Classes Comuns do Ensino Regular e SSE, apresentada no Gráfico 2, verifica-se que as Classes Comuns do Ensino Regular registraram os maiores aumentos nos números de matrículas entre 2009 e 2012, já em 2013, apesar do aumento, o número de matrículas foi apenas um pouco maior que o registrado em 2012. Em relação aos SSE, as reduções mais expressivas ocorreram entre 2009 e 2011. Entretanto, em 2012 houve aumento de 7.948 matrículas em relação ao ano anterior. Em 2013, apesar de registrar nova queda, o número de matrículas em SSE se manteve semelhante ao ano anterior.

A tabela a seguir apresenta a variação no total de matrículas da Região Nordeste entre 2009 e 2013, conforme cada modalidade de ensino e dependência administrativa. 
Tabela 3 - Variação Total do Número de Matrículas da Região Nordeste Modalidade de Ensino versus Dependência Administrativa

\begin{tabular}{c|r|r|r|r}
\hline \multicolumn{5}{c}{ Variação de Matrículas: 2009 - 2013 } \\
\hline & \multicolumn{5}{|c}{ Dependência Administrativa } \\
\hline Modalidade & \multicolumn{1}{|c|}{ Federal } & \multicolumn{1}{c}{ Estadual } & \multicolumn{1}{c}{ Municipal } & \multicolumn{1}{c}{ Privada } \\
\hline Educação Básica & 34.633 & -938.424 & -832.909 & 365.875 \\
\hline EEE & 0 & -943 & -1.303 & -11.375 \\
\hline Classe Especial & 0 & -4.680 & -3.520 & -546 \\
\hline Classe Comum & 79 & 13.741 & 69.523 & 5.738 \\
\hline
\end{tabular}

Fonte: Sinopses Estatísticas do Censo Escolar entre 2009 e 2013, autoria própria.

De modo geral, conforme os dados da Tabela 3, verifica-se que foram registradas consecutivas reduções no número de matrículas na EB no período estudado. Em 2013, os dados apontam que houve redução de 1.370 .825 matrículas em relação à a 2009 - eram 16.339.661 e passaram a ser 14.968.836. Quando analisadas as distribuições dessas matrículas, constata-se que a redução atingiu as dependências estadual e municipal, enquanto que a dependência federal e a esfera privada registraram sucessivos aumentos nas matrículas. Cabe ressaltar que, embora a esfera privada tenha sofrido aumento em todos os anos, a esfera pública, desde 2009, é a responsável por mais de $80 \%$ do total de matrículas na EB da Região Nordeste.

Entre 2009 e 2013, foram registradas consecutivas reduções nos números de matrículas em EEE - as matrículas foram de 25.665 para 12.044. Os dados apresentados na Tabela 3 registram que em 2013 foram contabilizadas 13.621 matrículas a menos que em 2009 nessa modalidade de ensino. Esta expressiva redução repercutiu, principalmente, na esfera privada, haja vista que 11.375 matrículas a menos foram registradas entre 2009 e 2013 somente nesse segmento. A esfera pública também foi afetada pela redução das matrículas, embora a dependência estadual tenha sofrido aumento no número de matrículas em 2012 e a dependência municipal em 2013, ambos pouco significativos. Vale salientar que, apesar de ter sido mais afetada pela redução, a esfera privada se mantém desde 2009 como principal responsável pelas matrículas nessa modalidade de ensino - mais de $60 \%$ em todos os anos.

De modo geral, bem como em EEE, as matrículas em Classes Especiais do Ensino Regular sofreram redução no período estudado. Os dados apresentados na Tabela 3 apontam que em 2013 foram registradas 8.746 matrículas a menos que em 2009 nessa modalidade de ensino - eram 15.729 e passaram a ser 6.983. No que tange à distribuição das matrículas, tanto a esfera pública quanto a esfera privada foram afetadas, embora aquela de maneira mais 
contundente. Enquanto a esfera privada registrou redução de 546 matrículas, a dependência estadual contabilizou a maior redução - 4.680 matrículas a menos - e a dependência municipal registrou redução de 3.520 matrículas em 2013 em relação aos dados de 2009. Diferentemente do que ocorre nas matrículas em EEE, a esfera pública é responsável pela maior parte das matrículas em Classes Especiais do Ensino Regular, representando, entre 2009 e 2013 , mais de $90 \%$ da totalidade de matrículas nessa modalidade de ensino.

Quando comparados os dados de 2013 com os dados de 2009, de acordo com a Tabela 3, verifica-se que o número de matrículas de alunos PAEE em Classes Comuns do Ensino Regular aumentou, aproximadamente, 4,4\% contabilizando, em 2013, 89.081 matrículas a mais que em 2009 - passaram de 91.092 para 180.173. Tal aumento refletiu principalmente no número de matrículas na dependência municipal - responsável, em todos os anos, por aproximadamente $80 \%$ do total de matrículas -, registrando aumento de 69.523. De modo menos expressivo, o aumento repercutiu nas matrículas dessa modalidade de ensino na dependência federal - aumento de 79 -, na dependência estadual - 13.74 a mais - e na esfera privada - 5.738 a mais em 2013 em relação aos dados de 2009. Embora a esfera privada tenha sofrido aumentos consecutivos nos números de matrículas, ela ainda responde por uma parcela mínima das matrículas de alunos PAEE em Classes Comuns do Ensino Regular menos de $7 \%$ do total - sendo, portanto, a esfera pública majoritariamente responsável pelas matrículas nessa modalidade de ensino.

Verifica-se que a Região Nordeste seguiu a tendência nacional em relação às matrículas, qual seja, redução nas matrículas de EB, aumento nas matrículas da Educação Especiais, das quais as Classes Comuns do Ensino Regular registraram aumentos consecutivos e os SSE reduções nas matrículas.

\section{3 Divisão das Matrículas da Educação Básica e de alunos PAEE entre Áreas Urbanas e Áreas Não-Urbanas}

As tabelas a seguir apresentam o total de matrículas da EB em áreas urbanas (Tabela 4) e em áreas não urbanas (Tabela 5) da Região Nordeste entre os anos de 2009 e 2013, bem como a distribuição das matrículas de alunos PAEE entre as Escolas Exclusivamente Especializadas (EEE), as Classes Especiais do Ensino Regular (CE) e as Classes Comuns do Ensino Regular (CC) no mesmo período. 
Tabela 4 - Distribuição do total de matrículas em áreas urbanas da região Nordeste por modalidade de ensino

Total de Matrículas em Áreas Urbanas da Região Nordeste por Modalidade de Ensino (2009 a 2013)

\begin{tabular}{c|c|c|r|r}
\hline Ano & EB & \multicolumn{1}{c|}{ EEE } & \multicolumn{1}{c|}{ CE } & \multicolumn{1}{c}{ CC } \\
\hline $\mathbf{2 0 0 9}$ & 12.445 .771 & 25.626 & 15.200 & 63.041 \\
\hline $\mathbf{2 0 1 0}$ & 12.002 .516 & 20.239 & 12.730 & 95.510 \\
\hline $\mathbf{2 0 1 1}$ & 11.892 .270 & 13.432 & 81 & 114.952 \\
\hline $\mathbf{2 0 1 2}$ & 11.810 .936 & 13.143 & 8.169 & 126.819 \\
\hline $\mathbf{2 0 1 3}$ & 11.618 .578 & 11.847 & 6.759 & 132.633 \\
\hline
\end{tabular}

Fonte: Sinopses Estatísticas do Censo Escolar entre 2009 e 2013, autoria própria.

Tabela 5 - Distribuição do total de matrículas em áreas Não urbanas da região Nordeste por modalidade de ensino

Total de Matrículas em Áreas Não-Urbanas da Região Nordeste por Modalidade de Ensino (2009 a 2013)

\begin{tabular}{c|c|r|r|c}
\hline Ano & EB & \multicolumn{1}{|c|}{ EEE } & CE & CC \\
\hline $\mathbf{2 0 0 9}$ & 3.893 .890 & 39 & 529 & 28.051 \\
\hline $\mathbf{2 0 1 0}$ & 3.707 .345 & 55 & 511 & 38.215 \\
\hline $\mathbf{2 0 1 1}$ & 3.577 .878 & 177 & 0 & 43.978 \\
\hline $\mathbf{2 0 1 2}$ & 3.416 .891 & 28 & 298 & 45.687 \\
\hline $\mathbf{2 0 1 3}$ & 3.350 .258 & 197 & 224 & 47.540 \\
\hline
\end{tabular}

Fonte: Sinopses Estatísticas do Censo Escolar entre 2009 e 2013, autoria própria.

No que tange às matrículas da EB, cabe destacar que as reduções ocorridas repercutiram tanto nas áreas urbanas quanto nas não urbanas no período estudado. Em relação à distribuição do total de matrículas entre as duas áreas, verifica-se que ocorreram oscilações no decorrer dos anos. As matrículas em áreas urbanas representaram 76,1\% do total das matrículas em 2009; 76,4\% em 2010; 76,9\% em 2011; 77,5\% em 2012; e 77,6\% em 2013. As matrículas em áreas não urbanas, por sua vez, corresponderam a 23,9\% do total de matrículas em 2009; 23,6\% em 2010; 23,1\% em 2011; 22,5\% em 2012; e 22,4\% em 2013. 
De maneira geral, as matrículas de alunos PAEE na Região Nordeste aumentaram no período entre 2009 e 2013, tanto em áreas urbanas, que registraram acréscimo de 47.372 matrículas, quanto em áreas não urbanas, com aumento de 19.342 matrículas. Esse aumento tem ocorrido de modo mais contundente nas Classes Comuns do Ensino Regular, em detrimento da redução nas matrículas em SSE. Num caráter mais detalhista, verifica-se que nas áreas urbanas as matrículas em Classes Comuns do Ensino Regular tiveram aumento de aproximadamente $110,4 \%$ em relação ao ano base, o que, numericamente, corresponde a 69.592 matrículas a mais.

Tal aumento se deu, como já citado, principalmente em detrimento da redução das matrículas nos SSE - cerca de 54,4\% a menos, o que representa 22.220 matrículas, sendo 13.779 a menos nas EEE e redução de 8.441 matrículas nas Classes Especiais do Ensino Regular. Em relação às matrículas de alunos PAEE em áreas não urbanas, como supracitado, houve acréscimo de aproximadamente $69,5 \%$ em relação ao ano base nas Classes Comuns do Ensino Regular, o que representa, numericamente, 19.489 matrículas a mais. Os SSE sofreram redução de $25,9 \%$ no período estudado - 147 matrículas a menos.

Essa redução deve-se exclusivamente às reduções ocorridas nas Classes Especiais do Ensino Regular, que tiveram 305 matrículas a menos, haja vista que, em contrapartida, as EEE registraram acréscimo de 158 matrículas em relação ao ano base. Cabe destacar que, embora as áreas urbana e não urbana assemelhem-se em relação à predominância das matrículas de alunos PAEE em Classes Comuns do Ensino Regular e à redução das matrículas em SSE nos últimos anos, elas diferenciam-se na distribuição das matrículas dos SSE, uma vez que nas áreas urbanas existem mais matrículas em EEE em relação às Classes Especiais do Ensino Regular, enquanto que nas áreas não urbanas ocorre movimento inverso - maior número de matrículas nas Classes Especiais do Ensino Regular, quando comparado às EEE.

Outro ponto de destaque é que, em relação ao total de matrículas na EB, as áreas não urbanas correspondem a uma parcela significativa - por volta de $23 \%$ do total. Em relação aos alunos PAEE, as áreas não urbanas representam cerca de $23,5 \%$ do total de matrículas.

À medida em que a Educação Especial passa a ser compreendida na perspectiva da Educação Inclusiva, integrando a proposta pedagógica da escola comum, a atual política (BRASIL, 2008) orienta as matrículas de alunos PAEE para a rede comum de ensino. Destarte, no período entre 2009 e 2013, ocorreram sucessivos acréscimos nas matrículas em Classes Comuns do Ensino Regular no Brasil, em detrimento das reduções nos SSE, sendo em 2010 o registro do maior aumento percentual em relação ao ano anterior. 
Entretanto, cabe salientar que apesar das sucessivas reduções nas matrículas nos SSE brasileiros, esses ainda respondiam por 194.421 matrículas em 2013. Desse total, cerca de $84,3 \%$ correspondia às matrículas em EEE, que na grande maioria destina suas matrículas para a esfera privada - a média brasileira no período estudado foi de aproximadamente $73,8 \%$ do total de matrículas nessa modalidade de ensino - indicando a forte presença de instituições comunitárias, confessionais ou filantrópicas sem fins lucrativos na escolarização de alunos PAEE.

Faz-se necessário destacar também que, à medida em que a oferta de EEE e Classes Especiais do Ensino Regular é bastante escassa nas áreas não urbanas, as matrículas são direcionadas para as Classes Comuns do Ensino Regular não apenas por orientações provenientes da política (BRASIL, 2008) e pelo movimento da sociedade em direção à Educação Inclusiva, mas também por essa carência de SSE.

Ainda sobre o ensino dos alunos PAEE que se encontram em áreas não urbanas, a "Política Nacional de Educação Especial na Perspectiva da Educação Inclusiva" (BRASIL, 2008) indica em suas diretrizes que:

A interface da educação especial na educação indígena, do campo e quilombola deve assegurar que os recursos, serviços e atendimento educacional especializado estejam presentes nos projetos pedagógicos construídos com base nas diferenças socioculturais desses grupos. (BRASIL, 2008, p.10).

Como verificado nos trabalhos de Liduenha (2012); Rebelo (2012) e Souza (2012), por exemplo, tal interface indicada como diretriz a ser seguida, pouco se realiza nas áreas não urbanas, sendo a Educação Especial marcada pelas dificuldades de acesso, pelo esquecimento, pela indiferença, pela falta de conexão entre os conteúdos oferecidos pela escola e as realidades dos alunos e, assim como ocorrido na $\mathrm{EB}$, sendo afetada pelo acelerado fechamento das escolas que, de acordo com o UNICEF (2014), acontece de maneira mais rápida do que a redução da população nessa área.

Ademais, embora a política indique a importância e a necessidade do AEE, realizado no contraturno, complementar e/ou suplementar ao ensino regular, dados de 2010 (UNICEF, 2014) indicam que o número de salas de recursos multifuncionais - essenciais para a realização desse atendimento - era muito baixo, especialmente no campo. Dessa maneira, é possível observar que os dados apontam que as escolas em áreas não urbanas - vale ressaltar, insuficientes para atender às demandas da população em idade escolar - estão ainda menos adequadas que as inseridas em áreas urbanas para receber os alunos PAEE. 
Os baixos números de crianças e jovens em idade escolar fora da escola não foram capazes de conter as reduções significativas no total de matrículas da EB no Nordeste, seguindo a tendência nacional, como apresentado. Segundo o UNICEF (2014), a Região Nordeste possui os maiores números absolutos de crianças e adolescentes fora da escola no Brasil, inclusive devido ao tamanho da população. Quanto à distribuição da responsabilidade entre as dependências administrativas, observa-se que os municípios foram majoritariamente responsáveis pelas matrículas entre 2009 e 2013.

Em relação às matrículas de alunos PAEE, foi registrado um aumento de aproximadamente 50,3\% entre 2009 e 2013. As Classes Comuns do Ensino Regular tiveram acréscimo de $97,8 \%$. Os SSE, por sua vez, reduziram $117,5 \%$ as matrículas no mesmo período, sendo a mais significativa entre 2010 e 2011, devido a uma drástica redução nas matrículas em Classes Especiais do Ensino Regular - que passaram de 13.241 para 81. Embora esse número tenha voltado a crescer de maneira expressiva no ano subsequente, cabe indagar sobre o destino das 13.160 matrículas que foram reduzidas dessa modalidade de ensino (também somadas à redução de 6.685 matrículas nas EEE). Pode-se indicar uma possível migração dessas matrículas para as Classes Comuns do Ensino Regular, que nesse período tiveram aumento de 28.105 matrículas em relação a 2010.

No que concerne às matrículas de alunos PAEE em Classes Comuns do Ensino Regular, verifica-se que a dependência municipal concentrou os maiores percentuais nacionais de responsabilidade por tal modalidade de ensino, uma vez que, entre 2009 e 2013, a média foi de $80,2 \%$ em relação ao total de matrículas.

A Região Nordeste destinou parte significativa das matrículas da EB para as áreas não urbanas, chegando a 23,1\% no período de 2009 a 2013. Em números absolutos, tal percentual correspondeu todos os anos a mais de 3.000.000 matrículas. De modo específico, os alunos PAEE em áreas não urbanas concentraram-se, majoritariamente, nas Classes Comuns do Ensino Regular - média de 98,9\% no período supracitado, em sua maioria, sob responsabilidade da dependência municipal. É interessante destacar que a redução de matrículas em Classes Especiais do Ensino Regular sofrida na região em 2011 afetou diretamente as áreas não urbanas, posto que, de 511 matrículas em 2010, elas foram reduzidas a zero no ano seguinte. Embora o número tenha voltado a crescer em 2012, verifica-se que, de modo geral, essa modalidade de ensino passou de 1,8\% em 2009, para 0,5\% do total de matrículas em 2013.

De maneira geral, A Região Nordeste é uma das regiões brasileiras que concentra os maiores índices - percentuais e em números absolutos - de matrículas da EB em áreas não 
$\operatorname{urbanas}^{7}$ e, consequentemente, de alunos PAEE nessas áreas. Destarte, as diretrizes e orientações provenientes da "Política Nacional de Educação Especial na Perspectiva da Educação Inclusiva” (BRASIL, 2008) sobre educação no campo, quilombola e indígena deveriam atingir de maneira direta essa região. Entretanto, ao passo em que é atingida por políticas educacionais estaduais e, principalmente, municipais, a efetivação de tais diretrizes, como a supracitada interface com a Educação Especial, pouco acontece nas áreas não urbanas, indicando que, possivelmente, a política (BRASIL, 2008) pouco tem influenciado em tais áreas.

No que diz respeito à analise possível de ser realizada colocando em foco diferentes dependências administrativas e as diversas modalidades de ensino, o que se pode depreender é que, de maneira geral, no que tange à esfera da dependência federal, a mesma tem exercido um papel não tão ampliado em relação à responsabilidade pelas matrículas na EB do Nordeste, nem em relação especificamente às matrículas de alunos PAEE $^{8}$.

Já o que se tem a respeito da dependência estadual permite verificar que a mesma foi a segunda maior responsável pelas matrículas na EB do país, atingindo a média de aproximadamente 40,2\% no período entre 2009 e 2013 . No que diz respeito às matrículas de alunos PAEE, a média de responsabilidade da dependência estadual pelas matrículas em EEE nos últimos cinco anos foi de 15,2\% - maior na Região Nordeste (37,2\%). Nas Classes Especiais do Ensino Regular, tal dependência registrou média percentual de 35,2\% no mesmo período - maior percentual no Centro-Oeste $(65,8 \%)$ e menor no Norte $(13,7 \%)$. Em relação às Classes Comuns do Ensino Regular, a dependência estadual, assim como ocorrido no total da EB, também se destaca como segunda principal responsável pelas matrículas, atingindo a média de aproximadamente 36,5\% entre 2009 e 2013 - no Nordeste, a média foi de 13,7\%.

Cabe destacar, no entanto, o papel da dependência municipal que respondeu, majoritariamente, pela maior parte das matrículas na $\mathrm{EB}$ nos últimos cinco anos, chegando à média nacional de 44,9\% - no Nordeste a média atingiu $58,1 \%$. No que tange aos alunos PAEE, verifica-se que nas EEE a média de matrículas sob responsabilidade da dependência municipal entre 2009 e 2013, no Nordeste, o percentual foi de 16,9\%. Nas Classes Especiais do Ensino Regular, a média de matrículas nessa dependência foi por volta de 53,1\%. Em

\footnotetext{
${ }^{7}$ A Região Norte é a outra região brasileira que concentra os maiores índices de matrículas em áreas não urbanas no período estudado, de acordo com as Sinopses Estatísticas do Censo Escolar de 2009 a 2013. Nas outras regiões brasileiras (Centro-Oeste, Sudeste e Sul) os índices de matrículas em áreas não urbanas são pouco expressivos.

${ }^{8}$ Vale ressaltar que a União, segundo a LDBEN/96 (BRASIL, 1996), garante apoio técnico e financeiro à EB, que fica sob a responsabilidade de Estados e Municípios.
} 
relação às matrículas em Classes Comuns do Ensino Regular, observa-se que a média chegou a 57,9\% nessa modalidade de ensino - tendo o Nordeste atingido a média de 80,2\%.

Vale ressaltar que, ao mesmo tempo que os municípios compõem a dependência com a maior responsabilidade pelas matrículas de alunos PAEE em Classes Comuns do Ensino Regular, são também os mais passíveis de questionamentos críticos sobre os poderes econômicos, de infraestrutura e de equipe com formação para atender as demandas necessárias para acolher esse desafio. (VELOSO, 2009).

Finalizando, a esfera privada foi também responsável por uma parcela pequena das matrículas na EB no período entre 2009 e 2013 - cerca de 14,3\%. Em relação aos alunos PAEE, constata-se que na esfera privada houve grande participação na responsabilidade pelas matrículas em EEE no período supracitado, com média percentual de 74,1\%. Em contrapartida, nas Classes Especiais do Ensino Regular, o percentual foi bastante reduzido, não ultrapassando os 11,6\%, ou seja, cenário inverso ao das EEE. Nas Classes Comuns do Ensino Regular, a média percentual foi ainda menor, chegando apenas a 5,2\%.

De modo geral verifica-se que a esfera pública se manteve como principal responsável pelas matrículas na EB no período de 2009 a 2013, atingindo a média de 85,7\%. Contudo, de maneira mais específica, observa-se que estados e municípios dividiram a responsabilidade pelas matrículas na $E B$, posto que a participação da dependência federal foi mínima. Tal cenário ocorreu como resultado de legislações educacionais, que não cabem ser exploradas aqui.

\section{Considerações Finais}

O trabalho desenvolvido reforçou a importância dos dados tratados, retirados das Sinopses Estatísticas do Censo Escolar, como meio para se obter panoramas acerca das matrículas de alunos PAEE tanto no contexto da realidade regional como do Brasil. Justamente por isso, como mencionado anteriormente, eles são a base para a elaboração e aprimoramento de leis e políticas educacionais. Entretanto, cabe mais uma vez apontar seus limites como, por exemplo, a imprecisão e a ambiguidade nas metodologias de coleta, conforme apontam Bueno e Meletti (2011).

Em relação aos resultados apresentados pela presente pesquisa, foi possível constatar que ocorreram aumentos consecutivos e expressivos nas matrículas de alunos PAEE na Região Nordeste no período entre 2009 e 2013, seguindo a tendência nacional. De modo mais detalhado, as matrículas nas Classes Comuns do Ensino Regular registraram aumentos no 
mesmo período, enquanto que as matrículas nos SSE sofreram reduções no número de matrículas. Verifica-se que o acréscimo de matrículas contabilizado nas Classes Comuns do Ensino Regular - 89.081 quando comparados os dados de 2013 aos de 2009 - é maior do que todo o acréscimo registrado nas matrículas de alunos PAEE como um todo - acréscimo de 66.714 no mesmo período. Ainda que todas as matrículas que foram reduzidas dos SSE fossem transferidas para as Classes Comuns do Ensino Regular, esse número ainda representa uma quantidade muito significativa.

Nesse sentido, cabe indagar sobre o preenchimento do Censo Escolar - esses dados caracterizam uma melhoria na caracterização de alunos PAEE ou uma possível "fabricação" de alunos com deficiência, pelas equipes escolares? A demanda cresceu e pode seguir crescendo pelos próximos anos se a escola continuar excluindo para, depois, numa tentativa de reversão, buscar incluí-los novamente. "Produzindo" a exclusão, a escola só tem contribuído para fazer com que "alunos de inclusão" sejam compreendidos como alunos que não fazem parte da totalidade de alunos matriculados na EB. Soma-se a tal circunstância, no entanto, a necessidade de considerar que também existem alunos PAEE em potencial fora da escola, em SSE ou, ainda, esquecidos no fundo de Classes Comuns do Ensino Regular, sem nenhum tipo de apoio, enquanto que esses alunos deveriam acessar e permanecer na escola e não serem expulsos, colocados à margem ao longo do processo ou fora de qualquer tipo de atendimento.

Para além de questionamentos referentes ao ingresso de crianças e adolescentes PAEE à escola, cabe também indagar sobre a inserção desses alunos nas Classes Comuns do Ensino Regular num cenário de baixa qualidade da escola de EB brasileira. Faz-se necessário, ainda, indagar sobre a interface entre Educação Especial e educação indígena, do campo e quilombola, prevista pela "Política Nacional de Educação Especial na Perspectiva da Educação Inclusiva" (BRASIL, 2008) que, como visto, não tem sido garantida nas áreas não urbanas.

Mediante o exposto, sem a pretensão de encerrar as discussões, mas, sim, ampliá-las, alguns questionamentos são válidos para reflexões futuras: Quais mudanças são necessárias para que a escola atenda às demandas dos alunos PAEE? Qual será o papel da "Política Nacional de Educação Especial na Perspectiva da Educação Inclusiva" (BRASIL, 2008) nos próximos anos? Que condições precisam ser aprimoradas na escola regular para que a inclusão deixe de ser pontual, com resultados positivos bastante ocasionais e fortuitos e comece a fazer parte do conjunto da escola? 


\section{Referências}

ATLAS DO DESENVOLVIMENTO HUMANO NO BRASIL. Destaques - Educação. Disponível em <http://www.atlasbrasil.org.br/2013/pt/destaques/educacao/> acesso em 24 jul. 2014.

BRASIL. MEC/SECADI/DPEE. Nota técnica n. ${ }^{\circ} 04 / 2014$. Brasília, DR, 2014. Disponível em $<$ http://portal.mec.gov.br/index.php?option=com_content\&view=article\&id=16761\&Itemid=1 123> acesso em 01 jul. 2014.

MEC/SEESP. Política Nacional de Educação Especial na Perspectiva da Educação Inclusiva. Brasília, DF, 2007. Disponível em <http://portal.mec.gov.br/seesp/arquivos/pdf/politica.pdf> acesso em 25 mar. 2013.

. Ministério da Educação. Instituto Nacional de Estudos e Pesquisas Educacionais. Sinopse Estatística da Educação Básica/Censo Escolar 2009. Brasília: MEC/INEP, 2010. Disponível em <http://portal.inep.gov.br/basica-censo-escolar-sinopse-sinopse> acesso em 18 dez. 2012.

Ministério da Educação. Instituto Nacional de Estudos e Pesquisas Educacionais. Sinopse Estatística da Educação Básica/Censo Escolar 2010. Brasília: MEC/INEP, 2011. Disponível em <http://portal.inep.gov.br/basica-censo-escolar-sinopse-sinopse> acesso em 18 out. 2012.

Ministério da Educação. Instituto Nacional de Estudos e Pesquisas Educacionais. Sinopse Estatística da Educação Básica/Censo Escolar 2011. Brasília: MEC/INEP, 2012. Disponível em <http://portal.inep.gov.br/basica-censo-escolar-sinopse-sinopse> acesso em 27 dez. 2012.

Ministério da Educação. Instituto Nacional de Estudos e Pesquisas Educacionais. Sinopse Estatística da Educação Básica/Censo Escolar 2012. Brasília: MEC/INEP, 2013. Disponível em <http://portal.inep.gov.br/basica-censo-escolar-sinopse-sinopse> acesso em 09 ago. 2013.

Ministério da Educação. Instituto Nacional de Estudos e Pesquisas Educacionais. Sinopse Estatística da Educação Básica/Censo Escolar 2013. Brasília: MEC/INEP, 2014. Disponível em <http://portal.inep.gov.br/basica-censo-escolar-sinopse-sinopse> acesso em 24 abr. 2014.

Presidência da República; Casa Civil; Subchefia para Assuntos Jurídicos. Decreto $n .^{o}$ 7.611, de 17 de novembro de 2011. Brasília: Presidência da República, 2011b. <http://www.planalto.gov.br/ccivil_03/_ato2011-2014/2011/decreto/d7611.htm> Acesso em 19 mai. 2016.

BUENO, J. G. Políticas de Escolarização de Alunos com Deficiência. In BUENO, J. G.; MELETTI, S. M. F. (Org) Políticas Públicas, Escolarização de Alunos com Deficiência e a Pesquisa Nacional. Araraquara, SP: Junqueira \& Marin, 2013. 
BUENO, J. G.; MELETTI, S. M. F. A Escolarização de Alunos com Deficiência Intelectual: Análises dos Indicadores Educacionais Brasileiros. In: BUENO, J. G.; MELETTI, S. M. F. (Org.) Políticas Públicas, Escolarização de Alunos com Deficiência e a Pesquisa Nacional. Araraquara, SP: Junqueira \& Marin, 2013.

O impacto das políticas públicas de escolarização de alunos com deficiência: uma análise de indicadores sociais no Brasil. Linhas críticas. Brasília, DF, v-17, n. ${ }^{\circ}$ 33, p.367-383, maio/agosto 2011. Disponível em <http://seer.bce.unb.br/index.php/linhascriticas/article/viewFile/5699/4711> acesso em 29 mar. 2013.

EDUCACENSO. O que é o Censo Escolar? Disponível em <http://portal.inep.gov.br/web/educacenso/censo-escolar> acesso em 22 de mai. 2014.

LIDUENHA, T. G. G. Escolarização de Alunos no Deficiência na Educação de Jovens e Adultos: Uma Análise dos Indicadores Educacionais Brasileiros. Londrina/PR, 2012. Disponível em <http://bancodeteses.capes.gov.br/> acesso em 01 jul. 2014.

MATOS, S. N.; MENDES, E. G. A Proposta de Inclusão Escolar no Contexto Nacional de Implementação das Políticas Nacionais. Dossiê Temático - Currículo e Prática Pedagógica. Revista Práxis Educacional,V. 10, n. ${ }^{\circ} 16,2014$. Disponível em: $<$ http://periodicos.uesb.br/index.php/praxis/article/viewFile/2889/2571> Acesso em: 20 jun. 2014.

MENDES, E. G. Breve histórico da educação especial no Brasil. Revista Educación y Pedagogia, V. 22, n. ${ }^{\text {57 }}$, maio/agosto 2010. Disponível em:

<http://aprendeenlinea.udea.edu.co/revistas/index.php/revistaeyp/article/viewFile/9842/9041> acesso em 29 mar. 2013.

PRIETO, R. G. Políticas de Inclusão Escolar no Brasil: Sobre Novos/Velhos Significados Para Educação Especial. In: ALMEIDA, M. A.; MENDES, E. G. Das Margens ao Centro: Perspectivas para as Políticas e Práticas Educacionais no Contexto da Educação Inclusiva. Araraquara, SP: Junqueira \& Marin, 2010.

REBELO, A. S. Os Impactos da Política de Atendimento Educacional Especializado: Análise dos Indicadores Educacionais de Matrículas de Alunos com Deficiência. Mato Grosso do Sul, 2012. Disponível em <http://bancodeteses.capes.gov.br/> acesso em 01 jul. 2014.

SOUZA, S. R. C. Educação Especial e a Escolarização de Pessoas com Deficiência que Residem no Campo: Uma Análise dos Indicadores Educacionais Brasileiros. Londrina/PR, 2012. Disponível em <http://bancodeteses.capes.gov.br/> acesso em 01 jul. 2014.

UNICEF. Iniciativa Global Pelas Crianças Fora da Escola - Brasil. Brasília, DF: UNICEF, 2012. Disponível em <http://foradaescolanaopode.org.br/downloads/br_oosc_ago12.pdf> acesso em 11 nov. 2014.

O Enfrentamento da Exclusão Escolar no Brasil. Brasília, DF: UNICEF Campanha Nacional pelo Direito à Educação, 2014. Disponível em 
<http://foradaescolanaopode.org.br/downloads/Livro_O_Enfrentamento_da_Exclusao_Escola r_no_Brasil.pdf > acesso em 11 nov. 2014.

VELOSO, F. et al. Educação Básica no Brasil: construindo o país do futuro. Rio de Janeiro: Elsevier, 2009.

VILELAS, J. O Processo de Construção do Conhecimento. Lisboa: Edições Sílabo, Lda, 2009. 